KILOH, L. G., BALL, J. R. \& GARside, R. F. (1962) Prognostic factors in treatment of depressive states with imipramine. British Medical Journal, $i, 1225-1227$.

Paykel, E. S., Klerman, G. L. \& Prusoff, B. A. (1974) Prognosis of depression and the endogenous-neurotic distinction. Psychological Medicine, 4, 57-64.

Division of Psychiatry

JAN SCOTT

The Royal Victoria Infirmary

Queen Victoria Road

Newcastle upon Tyne NE1 4LP

\section{Tourette's syndrome and the amygdaloid complex}

SIR: We would like to comment on the paper by Jadresic (Journal, October 1992, 161, 532-534) in which she has proposed that the 'amygdaloid complex' is central to the generation of the symptoms of Tourette's syndrome (TS).

Dr Jadresic advocates a pivotal role for the amygdala on the basis that vocalisations elicited from the amygdala are clearly related to emotional state in animals, and that vehement swearing with angry affect accompanied amygdaloid stimulation in one subject who was suffering from an aggressivity disorder. We would argue that these findings militate against a primary involvement of the amygdala. Tourette's syndrome vocalisations are not necessarily accompanied by aggressive affect; indeed, Nuwer (1982) has stated that "the form of coprolalia (in TS) differs from that of purely emotionally generated obscenity in its cadence, pitch, volume and context, as well as in other ways".

Conversely, Dr Jadresic states that electrical stimulation of the cingulum, pontive tegmentum and the periqueductal grey matter (PAG) trigger vocalisations which are devoid of emotional content. However, it may be noted that her source, a review by Bonnet (1982), took information from a further review by Jurgens \& Ploog (1981), which in turn was taken from the experiments of Jurgens (1976). The original work used a form of place-preference test in a shuttle-box to estimate the rewarding or aversive properties of braiil stimulation which was accompanied by vocalisation in the squirrel monkey. This is rather different from claiming that the vocalisations so induced were devoid of emotional content. Two groups of areas elicited vocalisation; in the first, which included amygdala, hypothalamus, substantia nigra, and rostral PAG, vocalisation was accompanied by motivational changes, while in the second, including the cingulate gyrus, caudal PAG, and adjacent parabrachial region, motivational changes where absent or variable. In our view the lack of any close coupling between TS vocalisations and affect suggests a possible involvement of this second group of brain areas in TS vocalisation.

With regard to Dr Jadresic's neurobiochemical observations, dopamine antagonist neuroleptics do indeed ameliorate the symptoms of TS, but are effective in only $60-70 \%$ of cases and rarely abolish them. There is also a possibility that their effectiveness is related to $5-\mathrm{HT}_{2}$ rather than dopamine receptor blockade (for review see Handley \& Dursun, 1992). That there is a dopamine input to the amygdala is not an argument for amygdaloid involvement, since such inputs exist to many other parts of the brain. Although an example is quoted of exacerbation of tics and induction of coprolalia by fluvoxamine, it may be noted that exacerbation, improvement, and no change, have been noted in other TS patients treated with selective serotonin-uptake inhibitors (Handley \& Dursun, 1992).

Clues to the brain areas and neurotransmitters which may be affected in TS would indeed be of enormous value. However, we do not believe that Dr Jadresic has made a case for a key role of the amygdaloid complex.

BONNET, K. A. (1982) Neurobiological dissection of Tourette's syndrome: a neurochemical focus on a human neuroanatomical model. Advances in Neurology, 35, 77-82.

HandLeY, S. L. \& DURSUN, S. M. (1992) Serotonin and Tourette's syndrome: movements such as head-shakes and wet-dog-shakes may model human tics. Advances in Biosciences, 85, 235-253.

JURGENS, U. (1976) Reinforcing concomitants of electrically elicited vocalizations. Experimental Brain Research, 26, 203-214.

- \& Ploog, D. (1981) On the neural control of mammalian vocalization. Trends in Neurosciences, 4, 135-137.

NUWER, M. R. (1982) Coprolalia as an organic symptom. Advances in Neurology, 35, 77-82.

Sheila L. HaNDLEY

ANDREW C. MCCREARY

SERDAR M. Dursun

Pharmaceutical Sciences Institute

Aston University

Aston Triangle

Birmingham B4 7ET

The Uffculme Clinic

Birmingham

HUGH RickaRDS

\section{Propofol and ECT}

SIR: We are able to support the retrospective observations of Mitchell et al (Journal, December $1992,161,861-862$ ) with the preliminary results of our prospective randomised comparison of methohexitone and propofol in terms of seizure duration and outcome in electroconvulsive therapy (ECT). It has often been demonstrated that seizure duration is 